\title{
Erzurum İli Çayır ve Meralarında Doğal Olarak Yetişen Bazı Baklagil ve Buğdaygil Yem Bitkilerinin Mineral Madde Kompozisyonlarının Belirlenmesi
}

\begin{tabular}{|c|c|}
\hline Araştırma / Research & \\
\hline $\begin{array}{l}\text { Geliş Tarihi / Received } \\
\text { 20.12.2016 }\end{array}$ & 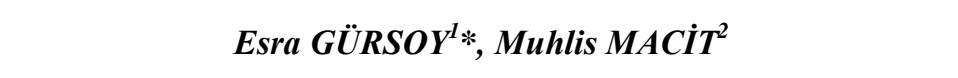 \\
\hline $\begin{array}{l}\text { Kabul Tarih / Accepted } \\
22.05 .2017\end{array}$ & $\begin{array}{l}{ }^{1} \text { Il Gida, Tartm ve Hayvancılık Müdürlüğü, Erzincan- Türkiye } \\
{ }^{2} \text { Atatürk Üniversitesi Ziraat Fakültesi Zootekni Bölümü, Erzurum- Türkiye }\end{array}$ \\
\hline $\begin{array}{l}\text { DOI } \\
10.28955 / \text { alinterizbd.279756 }\end{array}$ & *e-posta:esra_gursoykaya@hotmail.com \\
\hline $\begin{array}{l}\text { ISSN 2564-7814 } \\
\text { e-ISSN 2587-2249 }\end{array}$ & \\
\hline
\end{tabular}

Öz: $\mathrm{Bu}$ çalışma Erzurum ilinde doğal olarak yetişen bazı baklagil ve buğdaygil yem bitkilerinin mineral madde içeriklerinin belirlenmesi amacıyla yürütülmüştür. Çalışmada, baklagil yem bitkilerinden yonca (Medicago sativa), melez yonca (Medicago varia), dağ İspanyol korungası (Hedysarum elegans), kuş fiği (Vicia cracca), tüylü fiğ (Vicia villosa), dağ fiği (Vicia alpestris), dağ üçgülü (Trifolium montanum), kafkas üçgülü (Trifolium ambiguum), üç başl1 üçgül (Trifolium trichocephalum), alaca taç otu (Coronilla varia), doğu taç otu (Coronilla orientatis) ve sarı çiçekli gazal boynuzu (Lotus corniculatus); buğdaygil yem bitkilerinden ise domuz ayrığ 1 (Dactylis glomerata), adi otlak ayrığ1 (Agropyron cristatum), kırmızı yumak (Festuca rubra), koyun yumağ1 (Festuca ovina), alaca brom (Bromus variegatus), mavi ayrık (Agropyron intermedium), çayır kelp kuyruğu (Phleum pratense), çayır salkım otu (Poa pratensis) incelenmiştir. Mevcut çalışmada elde edilen veriler SPSS 12.0 paket programında varyans analizine tabi tutulmuştur. Gruplara ait ortalamaların karşılaştırılmasında ise Duncan çoklu karşılaştırma testi kullanılmıştır.

Baklagil yem bitkileri için belirlenen makro besin elementlerinden Azot (N), Fosfor (P), Potasyum (K), Kalsiyum (Ca), Magnezyum (Mg) ve Kükürt (S) oranları sirasıyla \%2,39-3,30; $\% 1,16-1,28 ; \% 0,70-2,69 ; \% 0,56-1,61 ; \% 0,11-0,51$ ve \%0,16-0,27 arasında değişmiştir, Yem bitkilerinin mikro besin elementlerinden Demir (Fe) 105,9-893,7 ppm, Bakır (Cu) 2,22-12,36 ppm, Çinko (Zn) 14,11-195 ppm, Mangan (Mn) 18,18-66,58 ppm, Bor (B) 5,91-40,39 ppm arasında bulunmuştur, Buğdaygil yem bitkileri için tespit edilen makro besin elementi oranları N \%1,76-2,19; P \%1,10-1,19; K \%1,99-3,25; Ca \%0,09-1,15, Mg \%0,07-0,26 ve S \%0,22-0,36 arasında değişmiştir, Yem bitkilerinin mikro besin elementlerinden $\mathrm{Fe}, \mathrm{Cu}, \mathrm{Zn}, \mathrm{Mn}$ ve $\mathrm{B}$ miktarlar1 74,90-630,6 ppm, 4-9,84 ppm, 31,49-335,6 ppm, 24,63-94,51 ppm, ve 0,35-26,64 ppm arasında tespit edilmiştir,

Sonuç olarak, doğal olarak yetişen bazı baklagil ve buğdaygil yem bitkilerinin makro ve mikro mineral oranlarını belirlemek amacıyla yürütülen çalışma hem baklagil hem de buğdaygil yem bitkileri arasında makro ve mikro mineraller bakımından önemli farklılıkların olduğunu göstermiştir.

Anahtar Kelimeler: Baklagil ve buğdaygil yem bitkileri, makro mineral, mikro mineral

\section{Determination of Mineral Contents of Some Legume and Cereal Forages Grown as Naturally in Pastures of Erzurum Province}

\begin{abstract}
This study was carried out to determine the mineral substances such as macro and micro minerals of legume and cereal forages grown as naturally in the pastures of Erzurum province. In present study, clover, (Medicago sativa), mountain hispanic sainfoin (Hedysarum elegans), bird vetch (Vicia cracca), hairy vetch (Vicia villosa), mountain vetch (Vicia alpestris), mountain clover (Trifolium montanum), caucasian clover (Trifolium ambiguum), the three-headed clover (Trifolium trichocephalum), tawny grass crown (Coronilla varia), the crown of the eastern horn of grass (Coronilla orientatis) and yellow flowers gazelle (Lotus corniculatus) from legume forages; cocksfoot (Dactylis glomerata), crested wheatgrass (Agropyron cristatum), red fescue (Festuca rubra), sheep ball (Festuca ovina), tawny bromine (Bromus variegatus), blue split (Agropyron intermedium), kelp tail grass (Phleum pratense),
\end{abstract}


meadow bluegrass (Poa pratensis) from cereal forages were investigated. The obtained data were subjected to an analysis of variance by using SPSS 12.0 package program. Significant differences between means were tested by using Duncan's Multiple Range Test.

Macro minerals such as Nitrogen (N), Phosphorus (P), Potassium (K), Calcium (Ca), Magnesium (Mg) and Sulfur (S) assigned for legume forages changed between 2.39- 3.30\%, $1.16-1.28 \%, 0.70-2.69 \%, 0.56-1.61 \%, 0.11-0.51 \%$ and $0.16-0.27 \%$, respectively. The amounts of micro mineral like Iron $(\mathrm{Fe})$, Virgin $(\mathrm{Cu})$, Zinc $(\mathrm{Zn})$, Manganese $(\mathrm{Mn})$ and Boron $(\mathrm{B})$ of legume forages were determined to be 105.9-893.7 ppm, 2.22-12.36 ppm, 14.11-195 ppm, 18.18-66.58 ppm and 5.91-40.39 ppm, respectively. Instances of macro minerals of cereal forages were found for N 1.76-of 2.19\%, P 1.10-1.19\%, K 1.99-3.25\%, Ca 0.09-1.15\%, Mg $0.07-0.26 \%$ and $\mathrm{S} 0.22-0.36 \%$ in present study. Micro minerals such as $\mathrm{Fe}, \mathrm{Cu}, \mathrm{Zn}, \mathrm{Mn}$ and $\mathrm{B}$ determined for cereal forages changed between 74.90-630.6 ppm, 4-9.84 ppm, 31.49-335.6 ppm, 24.63-94.51 ppm and 0.35-26.64 ppm, respectively.

In conclusion, present study carried out to determine the macro and micro mineral contents of legume and cereal forages grown as naturally showed that differences in terms of macro and micro minerals among both legume forages and cereal forages were significant.

Keywords: Legume and cereal forages, macro mineral, micro mineral

\section{GíRiş}

Ülkemiz çayır ve meralarında doğal olarak farklı çok sayıda kaliteli yem bitkisi yetişmesine rağmen, çok az sayıda yem bitkisinin tarımı yapılmakta ve yem bitkileri tarımının tarla tarımı içindeki oranı da \%6’yı geçmemektedir. Tarımı gelişmiş ülkelerle kıyaslandığında bu oranın düşük olduğu, arttırılması içinde yeni yem bitkisi tür ve çeşitlerinin tarla tarımına dahil edilmesi gerektiği bildirilmektedir (Başaran ve ark., 2006).

Vücutta biyolojik olarak sentezlenemediği için rasyonla hayvana verilmesi gereken mineraller, hayvanların sağlıklı olarak yaşamlarını sürdürebilmeleri ve genetik yapılarında barındırdıkları maksimum performansı ortaya koymaları için gerekli inorganik maddelerdir. Vitaminler ile birlikte çalışarak hem vitaminlerin hem de diğer besin maddelerinin etkin bir şekilde değerlendirilmesini sağlamak minerallerin en önemli fonksiyonlarından birisidir. Çiftlik hayvanları için gerekli olan mineral madde ihtiyacı sabit olmamakla birlikte verim, canlı ağırlık, çevre ve yemle ilgili faktörlere bağlı olarak değişebilmektedir. Uzun süre yetersiz beslenen hayvanların mineral madde gereksinimleri de artmaktadır (Aksoy ve ark., 2000; Açıkgöz, 2001; Boğa ve Filik, 2011; Türkmen ve ark., 2011).

Ülkemiz çayır ve meralarında doğal olarak yetişen çok sayıda kaliteli yem bitkisi olmasına rağmen, kültürü yapılan yem bitkileri oldukça sınırlı sayıda bitki tür ve çeşidinden oluşmaktadır. Mevcut çalışma, Erzurum ili ve ilçelerine ait meralarda doğal olarak yetişen bazı baklagil ve buğdaygil yem bitkilerinin makro ve mikro mineral madde içeriklerinin ortaya konulması amacıyla yürütülmüştür.

\section{MATERYAL VE YÖNTEM}

Araştırmanın yem materyalini, 2012 yılı Haziran-Temmuz aylarında Erzurum İli merkez ilçesi, Tortum ilçesindeki meradan (1449 m, 40 255773K, 41 262527D) yonca (Medicago sativa), dağ İspanyol korungası (Hedysarum elegans) ve tüylü fiğ (Vicia villosa), Pasinler ilçesindeki meralardan (2010 m, 39 943919K, 41 405451D, 2247 m, 40 096316K, $41789316 \mathrm{D}$ ve 2020 m, 39 897225K, 41 71228D) dağ üçgülü (Trifolium montanum), kuş fiği (Vicia cracca), alaca taç otu (Coronilla varia L.) ve melez yonca (Medicago varia), Şenkaya ilçesindeki meradan (2543 m, 40 54642K, 42 412421D) sarı çiçekli gazal boynuzu (Lotus corniculatus), Çat ilçesindeki meralardan (2105 m, 39 79306K, 41 15004D ve 1919 m, 39 635652K, 40 7555496D) doğu taç otu (Coronilla orientatis), dağ fiği (Vicia alpestris) ve üç başlı üçül (Trifolium trichocephalum), Oltu ilçesindeki meradan (2431 m, 40 419009K, 42 170774D) kafkas üçgülü (Trifolium ambiguum) 12 baklagil yem bitkileri çiçeklenme döneminde hasat edilmiştir. Buğdaygil yem bitkilerinde ise başaklanma devresinde Tortum ilçesindeki meradan (1839 m, 40296945 K, 45067D) adi otlak ayrığı (Agropyron cristatum) ve alaca brom (Bromus variegatus), Narman ilçesindeki meradan (1777 m, 403300462K, 41 99512D) kırmız1 yumak (Festuca rubra) ve koyun yumağı (Festuca ovina), Çat ilçesindeki meradan (1933 m, 39 81728K, 41 14688D ve 2114 m, 39 80279K, 41 16932D) mavi ayrık (Agropyron intermedium), domuz ayrığ (Dactylis glomerata), çayır kelp kuyruğu (Phleum pratense) ve çayır salkım otu (Poa pratensis) 8 buğdaygil yem bitkisi hasat alanındaki bitki kompozisyonunu temsil edecek şekilde her bir bitki için 10 değişik yerden örnek alınmış ve harmanlanmıştır (Canbolat ve Karaman 2009). Yem 
materyallerinin örneklendiği alanların koordinatları ve rakımları GPS (Global Positioning System) Allınterı cihazı ile belirlenerek kaydedilmiştir.

\section{Yem Örneklerine Ait Mineral Madde İçeriklerinin Belirlenmesi}

Kurutma $\left(105^{\circ} \mathrm{C}^{\prime}\right.$ de 3 saat) işleminden sonra yem bitkisi örnekleri, $1 \mathrm{~mm}$ elekten geçecek şekilde öğütülmüşsür. Yemlerin mineral madde tayinleri üç tekerrürlü olarak yapılmıştır. Yem örneklerinin $\mathrm{N}$ içerikleri, salisilik-sülfürik asit karışımı ile yaş yakmaya tabi tutulduktan sonra mikro kjeldahl yöntemi ile belirlenmiștir (AOAC, 1990). Söz konusu bitkilerin $\mathrm{P}, \mathrm{K}, \mathrm{Ca}, \mathrm{S}, \mathrm{Mg}, \mathrm{Fe}, \mathrm{Cu}, \mathrm{Mn}, \mathrm{Zn}$ ve B içerikleri nitrik asit:hidrojen peroksit $(2: 3)$ karışımı ile 3 farklı adımda (1. adım; $145^{\circ} \mathrm{C}$ 'de $\% 75$ mikrodalga gücün de 5 dakika, 2. adım; $180^{\circ} \mathrm{C}$ 'de $\% 90$ mikrodalga gücünde 10 dakika ve 3 . Adım; $100^{\circ} \mathrm{C}$ 'de $\% 40$ mikrodalga gücünde 10 dakika) 40 bar basınca dayanıklı mikrodalga yaş yakma ünitesinde (speedwave MWS-2 Berghof productts + Instruments Harresstr.1. 72800 Enien Germany) muameleye tabi tutulduktan (Mertens, 2005a) sonra ICP OES spektofotometresinde (Inductively Couple Plasma spectrophotometer) (Perkin-Elmer, Optima 2100 DV, ICP/OES, Shelton, CT 064844794, USA) okunmak suretiyle belirlenmiştir (Mertens, 2005b).

\section{İstatistik Analizler}

Araştırmada elde edilen veriler SPSS 12.0 paket programında varyans analizine (General linear model) (Statisca 1933) tabi tutulmuştur. Gruplara ait ortalamaların karşılaştırılmasında ise Duncan çoklu karşılaştırma testi (Duncan, 1955) kullanılmıştır.

\section{ARASTIRMA BULGULARI VE TARTISMA}

Doğal olarak çayır ve meralarda yetişen baklagil ve buğdaygil yem bitkilerine ait makro ve mikro besin elementi içerikleri Çizelge 1, 2, 3 ve 4 'de verilmiştir. İncelenen baklagil ve buğdaygil kaba yemleri arasında makro ve mikro besin elementleri bakımından meydana gelen farklılıklar önemli bulunmuştur $(\mathrm{P}<0.01)$.

Çizelge 1. Baklagil yem bitkilerinin makro besin elementi içerikleri, \% (KM'de).

\begin{tabular}{|c|c|c|c|c|c|c|}
\hline \multirow[b]{3}{*}{ Yem Bitkileri } & \multicolumn{6}{|c|}{ Makro Besin Elementleri } \\
\hline & & $\mathbf{P}$ & $\mathbf{K}$ & $\mathbf{C a}$ & Mg & $\mathbf{S}$ \\
\hline & $\mathbf{N}$ & & & & & \\
\hline $\begin{array}{l}\text { Dağ İspanyol } \\
\text { korungası }\end{array}$ & $2,41^{\mathrm{g}}$ & $1,28^{\mathrm{a}}$ & $0,70^{f}$ & $0,71^{\mathrm{c}}$ & $0,17^{\text {ef }}$ & $0,25^{\text {abc }}$ \\
\hline Tüylü fiğ & $2,94^{\mathrm{bc}}$ & $1,19^{\mathbf{b c}}$ & $2,26^{\mathrm{cd}}$ & $0,71^{\mathrm{c}}$ & $0,21^{\mathrm{de}}$ & $0,27^{\mathrm{a}}$ \\
\hline Yonca & $2,86^{\text {bcde }}$ & $1,17^{\mathbf{b c}}$ & $1,86^{\mathrm{e}}$ & $1,05^{\mathbf{b}}$ & $0,40^{\mathbf{b}}$ & $0,25^{\text {abc }}$ \\
\hline Dağ üçgülü & $2,39^{\mathbf{g}}$ & $1,16^{\mathrm{c}}$ & $2,21^{\mathrm{d}}$ & $0,56^{\mathrm{d}}$ & $0,11^{\mathrm{f}}$ & $0,19^{\text {de }}$ \\
\hline $\begin{array}{l}\text { Sarı çiçekli gazal } \\
\text { boynuzu }\end{array}$ & $2,54^{\mathrm{fg}}$ & $1,17^{\mathrm{bc}}$ & $2,69^{\mathrm{a}}$ & $0,80^{\mathbf{c}}$ & $0,19^{\mathrm{e}}$ & $0,19^{\text {cde }}$ \\
\hline Doğu taç otu & $2,93^{\text {bcd }}$ & $1,18^{\mathbf{b c}}$ & $2,36^{\mathbf{b c}}$ & $1,61^{\mathrm{a}}$ & $0,27^{\mathrm{cd}}$ & $0,25^{\mathbf{a b}}$ \\
\hline Dağ fiği & $3,15^{\text {ab }}$ & $1,18^{\mathbf{b c}}$ & $2,40^{b}$ & $0,58^{d}$ & $0,17^{\text {ef }}$ & $0,18^{\mathrm{de}}$ \\
\hline Kus fiği & $2,63^{\text {defg }}$ & $1,19^{\mathbf{b c}}$ & $1,85^{\mathrm{e}}$ & $1,08^{\mathbf{b}}$ & $0,26^{\mathrm{cd}}$ & $0,23^{\text {abcd }}$ \\
\hline Kafkas üçgülü & $2,68^{\text {cdefg }}$ & $1,18^{\mathbf{b c}}$ & $1,81^{\mathrm{e}}$ & $1,08^{b}$ & $0,51^{\mathrm{a}}$ & $0,20^{\text {bcde }}$ \\
\hline Alaca taç otu & $3,30^{\mathrm{a}}$ & $1,22^{\mathrm{abc}}$ & $2,19^{d}$ & $0,71^{\mathrm{c}}$ & $0,28^{\mathrm{cd}}$ & $0,21^{\text {abcde }}$ \\
\hline Üç başlı üçgül & $2,77^{\text {cdef }}$ & $1,23^{\text {abc }}$ & $1,93^{\mathrm{e}}$ & $0,98^{b}$ & $0,26^{\mathrm{cd}}$ & $0,16^{\mathrm{e}}$ \\
\hline Melez yonca & $2,58^{\mathrm{efg}}$ & $1,24^{\mathbf{a b}}$ & $2,35^{\mathbf{b c}}$ & $0,71^{\mathrm{c}}$ & $0,29^{\mathbf{c}}$ & $0,25^{\text {ab }}$ \\
\hline SHO & 0,071 & 0,019 & 0,032 & 0,029 & 0,016 & 0,012 \\
\hline Önemlilik Düzeyi & $* *$ & $* *$ & $* *$ & $* *$ & $* *$ & $* *$ \\
\hline
\end{tabular}


Çizelge 2. Buğdaygil yem bitkilerinin makro besin elementi içerikleri, \% (KM'de).

Makro Besin Elementleri

\begin{tabular}{lllllll}
\hline Yem Bitkileri & $\mathbf{N}$ & $\mathbf{P}$ & $\mathbf{K}$ & $\mathbf{C a}$ & $\mathbf{M g}$ & $\mathbf{S}$ \\
\hline Adi otlak ayrığı & $1,95^{\text {ab }}$ & $1,19^{\mathbf{a}}$ & $2,22^{\text {cd }}$ & $0,40^{\mathbf{b}}$ & $0,13^{\text {bc }}$ & $0,25^{\text {bc }}$ \\
\hline Kırmızı yumak & $1,89^{\text {ab }}$ & $1,10^{\mathbf{c}}$ & $2,23^{\text {cd }}$ & $0,22^{\text {cd }}$ & $0,07^{\mathbf{c}}$ & $0,26^{\text {bc }}$ \\
\hline Alaca brom & $2,08^{\text {ab }}$ & $1,14^{\text {abc }}$ & $2,52^{\mathbf{b}}$ & $0,36^{\mathbf{b}}$ & $0,15^{\text {bc }}$ & $0,26^{\text {bc }}$ \\
\hline Mavi ayrık & $2,15^{\mathbf{a}}$ & $1,19^{\mathbf{a}}$ & $3,25^{\mathbf{a}}$ & $0,19^{\text {de }}$ & $0,09^{\mathbf{c}}$ & $0,36^{\mathbf{a}}$ \\
\hline Çayır kelp kuyruğu & $1,89^{\text {ab }}$ & $1,13^{\text {abc }}$ & $2,23^{\text {cd }}$ & $0,14^{\text {ef }}$ & $0,13^{\text {bc }}$ & $0,29^{\text {abc }}$ \\
\hline Domuz ayrığı & $2,19^{\mathbf{a}}$ & $1,15^{\text {abc }}$ & $2,44^{\text {bc }}$ & $1,15^{\mathbf{a}}$ & $0,26^{\mathbf{a}}$ & $0,28^{\text {abc }}$ \\
\hline Çayır salkım otu & $1,76^{\mathbf{b}}$ & $1,17^{\text {ab }}$ & $2,55^{\mathbf{b}}$ & $0,27^{\mathbf{c}}$ & $0,19^{\text {ab }}$ & $0,32^{\text {ab }}$ \\
\hline Koyun yumağı & $1,76^{\mathbf{b}}$ & $1,11^{\text {bc }}$ & $1,99^{\mathbf{d}}$ & $0,09^{\mathbf{f}}$ & $0,08^{\mathbf{c}}$ & $0,22^{\mathbf{c}}$ \\
\hline SHO & 0,076 & 0,015 & 0,063 & 0,017 & 0,019 & 0,024 \\
\hline Önemlilik Düzeyi & $* *$ & $* *$ & $* *$ & $* *$ & $* *$ & $*$
\end{tabular}

a-f Aynı sütunda farklı harfler ile gösterilen ortalamalar arasındaki farklılıklar önemlidir. SHO: Standart Hata Ortalaması, N: Azot, P: Fosfor, K: Potasyum, Ca: Kalsiyum, Mg: Magnezyum, S: Kükürt. **: P<0.01, *: P<0.05

Çizelge 3. Baklagil yem bitkilerinin mikro besin elementi içerikleri, (KM'de)

Mikro Besin Elementleri (ppm)

\begin{tabular}{|c|c|c|c|c|c|}
\hline Yemler & $\mathbf{F e}$ & $\mathbf{C u}$ & $\mathbf{Z n}$ & Mn & B \\
\hline Dağ İspanyol korungası & $251,3^{1}$ & $2,22^{f}$ & $14,11^{\mathrm{h}}$ & $33,33^{\text {def }}$ & $8,71^{\mathrm{de}}$ \\
\hline Tüylü fiğ & $302^{\mathrm{g}}$ & $7,03^{\text {bcd }}$ & $20,05^{\mathrm{g}}$ & $36,05^{\mathrm{de}}$ & $9,18^{\mathrm{de}}$ \\
\hline Yonca & $665,2^{c}$ & $8,86^{\mathbf{b}}$ & $19,21^{\mathrm{g}}$ & $27,11^{\text {fgh }}$ & $27,09^{\mathbf{b}}$ \\
\hline Dağ üçgülüi & $167,2^{\mathrm{h}}$ & $5,64^{\text {cde }}$ & $53,46^{\mathrm{c}}$ & $18,18^{\mathrm{h}}$ & $10,90^{\text {de }}$ \\
\hline $\begin{array}{l}\text { Sarıçiçekli gazal } \\
\text { boynuzu }\end{array}$ & $105,9^{\mathrm{m}}$ & $5,53^{\text {cde }}$ & $61,59^{b}$ & $39,22^{\text {cd }}$ & $12,02^{d}$ \\
\hline Doğu taç otu & $331,9^{f}$ & $7,57^{\text {bcd }}$ & $42,23^{d}$ & $66,58^{\mathrm{a}}$ & $10,20^{\mathrm{de}}$ \\
\hline Dağ fiği & $203,2^{\mathbf{k}}$ & $4,25^{\mathrm{ef}}$ & $195^{\mathrm{a}}$ & $54,78^{\text {ab }}$ & $6,71^{f}$ \\
\hline Kuş fiği & $893,7^{\mathrm{a}}$ & $7,76^{\text {bc }}$ & $24,70^{f}$ & $46,41^{\mathrm{c}}$ & $17,02^{\mathbf{c}}$ \\
\hline Kafkas üçgülü & $371,7^{\mathrm{d}}$ & $12,36^{\mathbf{a}}$ & $24,29^{f}$ & $29,01^{\text {efg }}$ & $40,39^{\mathrm{a}}$ \\
\hline Alaca taç otu & $273,5^{1}$ & $5,18^{\mathrm{de}}$ & $30,12^{\mathrm{e}}$ & $29,42^{\mathrm{efg}}$ & $6,54^{f}$ \\
\hline Üç başlı üçgül & $752,4^{b}$ & $6,71^{\text {bcde }}$ & $46,36^{\mathrm{d}}$ & $60,56^{b}$ & $5,91^{\mathrm{f}}$ \\
\hline Melez yonca & $344,7^{\mathrm{e}}$ & $7,90^{\mathrm{bc}}$ & $22,22^{\mathrm{fg}}$ & $24,29^{\text {gh }}$ & $21,23^{\mathbf{c}}$ \\
\hline SHO & 2,681 & 0,572 & 1,001 & 2,009 & 1,185 \\
\hline Önemlilik Düzeyi & $* *$ & $*:$ & $* *$ & $* *$ & $* *$ \\
\hline
\end{tabular}

a-m Aynı sütunda farklı harfler ile gösterilen ortalamalar arasındaki farklılıklar önemlidir. SHO: Standart Hata Ortalaması, Fe: Demir, Cu: Bakır, Zn: Çinko, Mn: Mangan, B: Bor. **: $\mathrm{P}<0.01$ 
Çizelge 4. Buğdaygil yem bitkilerinin mikro besin elementi içerikleri, (KM'de)

\begin{tabular}{|c|c|c|c|c|c|}
\hline \multirow[b]{2}{*}{ Yem Bitkileri } & \multicolumn{5}{|c|}{ Mikro Besin Elementleri (ppm) } \\
\hline & $\mathbf{F e}$ & $\mathrm{Cu}$ & Zn & Mn & $\mathbf{B}$ \\
\hline Adi otlak ayrı̆̆ı & $630,6^{\mathbf{a}}$ & $6,22^{\mathbf{b c}}$ & $43,44^{\mathrm{de}}$ & $57,13^{b}$ & $0,83^{\mathrm{c}}$ \\
\hline Kırmızı yumak & $78,10^{\mathbf{e}}$ & $7,59^{\mathbf{b}}$ & $240,1^{\text {c }}$ & $24,63^{\mathrm{d}}$ & $1,56^{\mathrm{bc}}$ \\
\hline Alaca brom & $332,1^{\mathbf{b}}$ & $4,00^{\mathbf{c}}$ & $40,22^{\mathrm{de}}$ & $43,53^{\mathrm{c}}$ & $4,17^{\mathbf{b}}$ \\
\hline Mavi ayrık & $626,7^{\mathrm{a}}$ & $7,06^{\mathbf{b}}$ & $296,6^{\mathbf{b}}$ & $26,19^{d}$ & $1,86^{\mathrm{bc}}$ \\
\hline Çayır kelp kuyruğu & $74,90^{\mathrm{e}}$ & $6,96^{b}$ & $42,73^{\mathrm{de}}$ & $34,06^{\mathrm{cd}}$ & $3,88^{\mathbf{b}}$ \\
\hline Domuz ayrığı & $333,5^{\mathbf{b}}$ & $6,59^{b}$ & $31,49^{\mathrm{e}}$ & $65,63^{b}$ & $26,64^{\mathrm{a}}$ \\
\hline Çayır salkım otu & $273,5^{\mathbf{c}}$ & $9,84^{\mathrm{a}}$ & $52,47^{\mathrm{d}}$ & $94,51^{\mathrm{a}}$ & $0,35^{\mathbf{c}}$ \\
\hline Koyun yumağı & $148,0^{\mathrm{d}}$ & $4,95^{\mathrm{c}}$ & $335,6^{\mathrm{a}}$ & $27,52^{\mathrm{d}}$ & $4,06^{b}$ \\
\hline SHO & 5,620 & 0,347 & 3,777 & 2,359 & 0,580 \\
\hline Önemlilik Düzeyi & $* *$ & $* *$ & $* *$ & $* *$ & $* *$ \\
\hline
\end{tabular}

a-e Aynı sütunda farklı harfler ile gösterilen ortalamalar arasındaki farklılıklar önemlidir. SHO: Standart Hata Ortalaması, Fe: Demir, Cu: Bakır, Zn: Çinko, Mn: Mangan, B: Bor. **: $\mathrm{P}<0.01$

Baklagil yem bitkileri örneklerine ait makro besin elementlerinden $\mathrm{N}, \mathrm{P}, \mathrm{K}, \mathrm{Ca}, \mathrm{Mg}$ ve $\mathrm{S}$ oranlar1 sirasiyla \%2.39-3.30, \%1.16-1.28, \%0.70-2.69, \%0.56-1.61, \%0.11-0.51 ve \%0.16-0.27 arasinda değişmiştir. En yüksek N içeriği \%3.30 ile alaca taç otunda, en düşük ise \%2.39 ile dağ üçgülünde; en yüksek $\mathbf{P}$ içeriğgi, \%1.28 ile dağ İspanyol korungasında, en düşük ise \%1.16 ile dağ üçgülünde; en yüksek K içeriği, \%2.69 ile sarı çiçekli gazal boynuzunda, en düşük ise \%0.70 ile dă̆ İspanyol korungasında; en yüksek Ca içeriği, \%1.61 ile doğu taç otunda, en düşük ise \%0.56 ile dağ üçgülünde; en yüksek Mg içeriği, \%0.51 ile kafkas üçgülünde, en düşük ise \%0.11 ile dağ üçgülünde ve en yüksek $\mathbf{S}$ içeriği, \%0.27 ile tüylü fiğde, en düşük ise \%0.16 ile üç başlı üçgülde tespit edilmiştir.

Buğdaygil yem bitkileri örneklerine ait makro besin elementlerinden N içeriği \%1.76-2.19, P içeriği \%1.10-1.19, K içeriği \%1.99-3.25, Ca içeriği \%0.09-1.15, Mg içeriği \%0.07-0.26 ve S içeriği \%0.220.36 arasında değişmiştir. En yüksek $\mathbf{N}, \% 2.19$ ile domuz ayrığında, en düşük ise \%1.76 ile çayır salkım otu ve koyun yumağında; en yüksek $\mathbf{P}, \% 1.19$ ile adi otlak ayrığı ve mavi ayrıkta, en düşük ise \%1.10 ile kırmızı yumakta; en yüksek K, \%3.25 ile mavi ayrıkta, en düşük ise \%1.99 ile koyun yumağında; en yüksek Ca, \%1.15 ile domuz ayrığında, en düşük ise \%0.09 ile koyun yumağında; en yüksek Mg (\%0.26) domuz ayrığında, en düşük ise (\%0.07) kırmızı yumakta ve en yüksek $\mathbf{S}, \% 0.36$ ile mavi ayrıkta, en düşük ise \%0.22 ile koyun yumağında tespit edilmiştir.

Baklagil yem bitkilerie ait mikro besin elementi miktarları $\mathrm{Fe}, \mathrm{Cu}, \mathrm{Zn}, \mathrm{Mn}$ ve B için sırasıyla 105.9893.7 ppm, 2.22-12.36 ppm, 14.11-195 ppm, 18.18-66.58 ppm ve 5.91-40.39 ppm arasında değişmiştir. En yüksek Fe miktarı, 893.7 ppm ile kuş fiğinde, en düşük ise 105.9 ppm ile sarı çiçekli gazal boynuzunda; en yüksek $\mathrm{Cu}$ içeriği, 12.36 ppm ile kafkas üçgülünde, en düşük ise 2.22 ppm ile dağ İspanyol korungasında; en yüksek Zn miktarı, 195 ppm ile dağ fiğinde, en düşük ise 14.11 ppm ile dağ İspanyol korungasında; en yüksek Mn içeriği, 66.58 ppm ile doğu taç otunda, en düşük ise 18.18 ppm ile dağ üçgülünde ve en yüksek B miktarı, 40.39 ppm ile kafkas üçgülünde, en düşük ise 5,91 ppm ile üç başlı üçgülde tespit edilmiştir.

Buğdaygil yem bitkileri için tespit edilen mikro besin elementi miktarları $\mathrm{Fe}, \mathrm{Cu}, \mathrm{Zn}$, Mn ve $\mathrm{B}$ için sirasiyla 74,90-630,6 ppm, 4-9,84 ppm, 31,49-335,6 ppm, 24,63-94,51 ppm ve 0,35-26,64 ppm arasında değişmiştir, En yüksek Fe içeriği, 630,6 ppm ile adi otlak ayrığında, en düşük ise 74,90 ppm ile çayır kelp kuyruğunda; en yüksek Cu miktarı, 9,84 ppm ile çayır salkım otunda, en düşük ise 4 ppm ile alaca bromda; en yüksek $\mathbf{Z n}$ içeriği, 335,6 ppm ile koyun yumağında, en düşük ise 31,49 ppm ile domuz ayrığında; en yüksek Mn miktarı, 94,51 ppm ile çayır salkım otunda, en düşük ise 24,63 ppm ile kırmızı yumakta ve en yüksek B içeriği, 26,64 ppm ile domuz ayrığında, en düşük ise 0,35 ppm ile çayır salkım belirlenmiştir.

\section{Baklagil ve Buğdaygil Yem Bitkilerinin Makro Besin Elementi İçerikleri}

Vücut ağırlığının her kilogramında 50 miligramdan daha fazla bulunan mineraller, makromineral (sodyum, fosfor, potasyum, kalsiyum, magnezyum, klor ve kükürt) olarak adlandırılır (Kutlu ve ark,; 2005). 
Ruminantların retikulorumenlerindeki mikroorganizmalar, baklagil yem bitkilerinin makro besin elementlerinden olan azotu, yemdeki gerçek proteinlerden ve protein tabiatında olmayan azotlu (NPN) maddelerden temin ettikleri azotu, diğer besin maddelerinin fermantasyonu sonucu meydana gelen karbon iskeletlerini ve yem/yiyeceklerle rumene gelen kükürtlü bileşikleri kullanarak esansiyel amino asitlerce zengin biyolojik değeri yüksek olan mikrobiyal protein sentezlerler, Mevcut çalışmadan elde edilen $\mathbf{N}$ değerleri buğdaygil ve baklagil yem bitkilerinde \%0,7-2,9 (Kowalenko, 1978) arasinda, buğdaygil yem bitkilerinde \%1-4, baklagil yem bitkilerinde \%1-5 arasında değiştiği bildirilmiştir, Çalışmadaki N değerleri birçok araştırmacının bulgularıyla paralellik göstermektedir (Kowalenko, 1978; Mayland and Cheeke, 1995), Genel olarak fosfor (P), sığırlarda döl veriminde, kemik ve dişlerin oluşumunda fonksiyon gösterir, Noksanlığında, özellikle pika (anormal iştak) sendromu görülür, Buğdaygil yem bitkilerinde P değerleri, \%0,2-0,4 (Mayland and Cheeke, 1995), \%1,6 (Bakoğlu ve ark,, 1999), \%0,072 (Bayraktar, 2005) ve \%0,07-0,66 (Alp ve ark,, 2001) arasında değiştiği bildirilmiştir, Baklagil yem bitkilerinde P içerikleri, \%0,3-0,5 (Mayland and Cheeke, 1995), \% 1,7 (Bakoğlu ve ark,, 1999), \%0,082 (Bayraktar, 2005), \%0,25 (Tekeli ve ark,, 2003) ve \%0,4 (Orak ve ark,, 2004) arasında olduğu bildirilmiştir.

P içerikleri, kimi araştırmacıların bulgularından yüksek (Tekeli ve ark,, 2003; Mayland and Cheeke, 1995; Alp ve ark,, 2001; Orak ve ark,, 2004; Bayraktar, 2005), bazı araştırıcıların bildirdiği değerlerden ise düşük (Bakoğlu ve ark,, 1999) olmuştur, K, asit-baz dengesinde görev almaktadır, Noksanlığında, tetani görülür, Buğdaygil yem bitkilerinde K değerleri, \%1-3 (Mayland and Cheeke, 1995), \%3,44 (Bakoğlu ve ark,, 1999) ve \%1-3,31 (Alp ve ark,, 2001) arasında değiştiği bildirilmiştir, Baklagil yem bitkilerinde K içerikleri, \%2-3,7 (Mayland and Cheeke, 1995), \%4,03 (Bakoğlu ve ark,, 1999) ve \%1,6 (Tekeli ve ark,, 2003, Orak ve ark,, 2004) arasında olduğu bildirilmiştir, Potasyum içerikleri birçok araştırıcının bulguları ile uyum içerisinde (Tekeli ve ark,, 2003; Alp ve ark,, 2001; Orak ve ark,, 2004), bazı araştırmacıların bulgularından ise düşük (Bakoğlu ve ark,, 1999; Mayland and Cheeke, 1995) bulunmuştur, Ca, süt veriminin yanı sıra iskelet, yumurta kabuğu ve dişlerin yapısına girer ve sinir uyarılarının iletiminde görev alır, Noksanlığında, raşitizm, osteomalasi ve hipokalsemi görülür, Buğdaygil yem bitkilerinde Ca değerleri, \%0,2-0,5 (Mayland and Cheeke, 1995), \%0,63 (Bakoğlu ve ark,, 1999), \%0,39 (Bayraktar, 2005) ve \%0,10-4,35 (Alp ve ark,, 2001) arasında değiştiği bildirilmiştir, Baklagil yem bitkilerinde Ca içerikleri, \%0,2-1,4 (Mayland and Cheeke, 1995), \%1,31 (Bakoğlu ve ark,, 1999), \%0,52 (Bayraktar, 2005), \%1,3 (Tekeli ve ark,, 2003) ve \%1 (Orak ve ark,, 2004) arasında olduğu bildirilmiştir.

Mevcut çalışmadan elde edilen kalsiyum oranları bazı araştırmacıların bulguları ile uyum içerisinde (Mayland and Cheeke, 1995; Alp ve ark,, 2001; Orak ve ark,, 2004), birçok araştırıcının bulgularından düşük (Bakoğlu ve ark,, 1999; Tekeli ve ark,, 2003; Bayraktar, 2005) bulunmuştur, Mg, enzim aktivatörü olarak görev alır, Noksanlığında, çayır tetanisi görülür (Underwood, 1981; Ozan, 1983; Altın, 1992; Kaçar ve Katkat, 1997; Aksoy ve ark,, 2000; Türkmen ve ark,, 2011), Buğdaygil yem bitkilerinde Mg değerleri, \%0,1-0,3 (Mayland and Cheeke, 1995), \%1,18 (Bakoğlu ve ark,, 1999) ve \%0,15-0,39 (Alp ve ark,, 2001) arasında değiştiği bildirilmiştir, Baklagil yem bitkilerinde $\mathrm{Mg}$ içerikleri, \%0,2-0,5 (Mayland and Cheeke, 1995), \%2,8 (Bakoğlu ve ark,, 1999), \%0,6 (Tekeli ve ark,, 2003) ve \%0,31 (Orak ve ark,, 2004) arasında olduğu bildirilmiştir, Magnezyum içeriklerinin bir çok araştırıcının bulguları ile uyum içerisinde (Mayland and Cheeke, 1995; Bakoğlu ve ark,, 1999; Alp ve ark,, 2001; Tekeli ve ark,, 2003; Orak ve ark,, 2004) olduğu belirlenmiştir, S, sistin, sistein ve metiyonin gibi kükürt içeren esansiyel aminoasitlerin yapısına katılır, Noksanlığında, yapağı ve tiftik verimi ve kalitesi düşer, Kükürt değerleri, Mayland and Cheeke (1995)'ın bulguları (\%0,1-0,4 ve $\% 0,2-0,5)$ ile uyum içerisinde bulunmuştur,

Bitkilerin yapısında bulunan besin elementi miktarlarının yetiştirildikleri bölge, toprak tipi, bölgenin iklim koşulları ile gübreleme, vejetasyon dönemi ve hasat zamanı gibi çeşitli faktörlere bağlı olarak değiştiği çok sayıda araştırıcı tarafından bilinmektedir (Akyıldız ve ark,, 1974; Church, 1991; Mc Donald et al,, 1995), Deneme kapsamında incelenen baklagil ve buğdaygil yem bitkilerinin makro element içerikleri ile bu konuda yapılan diğer çalışmalardan elde edilen sonuçlar arasındaki farklılıklar yukarıda bahsedilen faktörlerden kaynaklanmış olabilir.

\section{Baklagil Ve Buğdaygil Yem Bitkilerinin Mikro Besin Elementi İçerikleri}

Vücut ağırlığının her kilogramında 50 miligramdan daha az bulunan mineraller, mikromineral (demir, bakır, çinko, mangan, bor, iyot, flor, selenyum, molibden, krom, vanadyum, kalay, silisyum, nikel ve arsenik) olarak adlandırılır (Kutlu ve ark., 2005). 
Fe, hemoglobin yapısında görev alır, sütle beslenen hayvanlarda, gebe hayvanlarda ve yumurtlama dönemindeki hayvanlarda, demire olan ihtiyaç çok yüksektir, Noksanlığında, anemi görülür, Buğdaygil yem bitkilerinde Fe değerleri, \%50-250 (Mayland and Cheeke, 1995) ve \%33,4-236,7 (Alp ve ark,, 2001) arasında değiştiği bildirilmiştir, Baklagil yem bitkilerinde Fe içerikleri, \%50-250 (Mayland and Cheeke, 1995), \%131,5 (Warly et al., 2010;) ve \%109-145 (Zia- Ul- Haq et al,, 2012) arasında olduğu bildirilmiştir, $\mathbf{C u}$, birçok enzimin koenzim kısmını, yani esansiyel kısmını oluşturur, tüy pigmentlerinin yapısına katılır ve hemoglobin sentezinde görev alır, Noksanlığında, sinirsel rahatsılıklar, anemi ve tüy ile yapağıda renk açılması görülür, Buğdaygil yem bitkilerinde $\mathrm{Cu}$ değerleri, \%3-15 (Mayland and Cheeke, 1995), \%13 (Murillo et al., 2012) ve \%1,83-15,45 (Alp ve ark., 2001) arasında değiştiği bildirilmiştir, Baklagil yem bitkilerinde $\mathrm{Cu}$ içerikleri, \%3-30 (Mayland and Cheeke, 1995), \%9,5 (Warly et al., 2010;) ve \%6-13 (Zia- Ul- Haq et al., 2012) arasında olduğu bildirilmiştir, Zn, antioksidan etkisi olup, enzimlerin yapısına katılmakta görev alır, Noksanlığında, yiyecek alınımında azalma, yemden yararlanmada düşme, üreme fonksiyonlarında bozulma, büyümede gerileme, tüy, deri, saç ve yünlerde anormallikler görülür, Buğdaygil yem bitkilerinde $\mathrm{Zn}$ değerleri, \%15-50 (Mayland and Cheeke, 1995), \%36,7 (Murillo et al., 2012) ve \%9,45-43,07 (Alp ve ark., 2001) arasında değiştiği bildirilmiştir, Baklagil yem bitkilerinde Zn içerikleri, \%15-70 (Mayland and Cheeke, 1995), \%29,9 (Warly et al,, 2010;) ve \%99-124 (Zia- Ul- Haq et al,, 2012) arasinda olduğu bildirilmiştir, Mn, kemik gelişiminde ve kolesterol sentezinde görev alır, Noksanlığında, perozis (tavuklarda ayak ve bacak iskeletlerinde biçim bozuklukları), yumurta kabuk oluşumunda bozulma ve üreme bozukluğu görülür, Buğdaygil yem bitkilerinde Mn değerleri, \%20-200 (Mayland and Cheeke, 1995) ve \%6,71-84,7 (Alp ve ark,, 2001) arasında değiştiği bildirilmiştir, Baklagil yem bitkilerinde Mn içerikleri, \%20-200 (Mayland and Cheeke, 1995) ve \%123 (Warly et al., 2010;) arasında olduğu bildirilmiştir, B, bitkilerde şekerin taşınması, hücre duvarının oluşumu, lignin oluşumu, karbonhidrat, solunum ve fenol metabolizması ile biyolojik membranların yapısal ve fonksiyonel özelliklerinin yanısıra, endokrin sistem, immun sistem ve beyinde de önemli işlevler üstlenmiştir, Bor, kalsiyum ve magnezyum metabolizmasında yer aldığından noksanlığında magnezyum eksikliğine yol açar, dolayısıyla bazı elementlerin ( $\mathrm{Ca}, \mathrm{Mg}$, vitamin $\mathrm{D}$, metiyonin, arginin) fonksiyonlarında da azalma görülür (Nielsen, 1994; Marschner, 1997; Aksoy ve ark., 2000; Demir, 2005; Türkmen ve ark., 2011; Çimrin ve Demirel, 2012), Buğdaygil yem bitkilerinde B değerleri, \%3-40 (Mayland and Cheeke, 1995) ve \%36,7 (Kızılgöz, 2009) arasında değiștiği bildirilmiştir, Baklagil yem bitkilerinde B içerikleri, \%30-80 (Mayland and Cheeke, 1995) arasında olduğu bildirilmiştir,

Araştırmada ele alınan baklagil yem bitkileri için tespit edilen mikro besin elementlerinden $\mathrm{Fe}, \mathrm{Cu}$, $\mathrm{Zn}, \mathrm{Mn}$ ve B miktarlarının baklagil yem bitkileri ile ilgili olarak yapılan bazı çalışmalarda bildirilen bulgularla uyum içerisinde (Mayland and Cheeke, 1995; Alp ve ark., 2001; Warly et al., 2010; ZiaUl- Haq et al., 2012) olduğu belirlenmiştir. Buğdaygil yem bitkileri için belirlenen $\mathrm{Fe}, \mathrm{Cu}, \mathrm{Zn}, \mathrm{Mn}$ ve B miktarlarının bazı araştırmacıların bildirdikleri sonuçlarla uyum içerisinde (Mayland and Cheeke, 1995; Alp ve ark., 2001; Kızılgöz, 2009; Murillo et al., 2012) olduğu tespit edilmiştir.

Bitkilerin kapsadıkları bitki besin elementi miktarları yetiştirildikleri bölge, toprak tipi, bölgenin iklim koşulları ile gübreleme, vejetasyon dönemi ve hasat zamanı gibi çeşitli faktörlere bağlı olarak değişiklik gösterdiği bilinmektedir. Deneme kapsamında incelenen baklagil ve buğdaygil yem bitkilerinin mikro element içerikleri ile bu konuda yapılan diğer çalışmalardan elde edilen sonuçlar arasındaki farklılığın söz konusu faktörlerden kaynaklandığı düşünülmektedir (Akyıldız ve ark., 1974; Church, 1991; McDonald et al., 1995).

\section{SONUÇ VE ÖNERILER}

Sonuç olarak, doğal olarak yetişen bazı baklagil ve buğdaygil yem bitkilerinin makro ve mikro mineral oranlarını belirlemek amacıyla yürütülen çalışmayla hem baklagil ve buğdaygil yem bitkilerinin kendi aralarında makro ve mikro mineraller bakımından önemli farklılıkların olduğu hem de şimdiye kadar makro ve mikro mineraller bakımından detaylı araştırması yapılmayan yem bitkilerinin mineral madde kompozisyonlarının tespit edildiği ve konu ile ilgili daha sonra yapılacak çalışmalara 1 şı tutacak bir kaynağın ortaya çıkması sağlanmıştır. Diğer taraftan mevcut çalışmadan elde edilen bulguların doğruluğunu kuvvetlendirmek ve hayvan besleme çalışmalarıyla ilişkilendirmek açısından ilerleyen zamanlarda disiplinler arası daha fazla araştırmanın yapılması gerektiği kanaatine varılmıştır. 


\section{TEŞEKKÜR}

Bu çalışma, 2011/334 proje numarasıyla Atatürk Üniversitesi BAP fonunca desteklenen ve Prof. Dr. Muhlis MACITT danışmanlığında Esra GÜRSOY tarafından hazırlanan Doktora Tezinden alınmıştır.

\section{KAYNAKLAR}

Açıkgöz, E., 2001. Yem Bitkileri. Uludağ Üniv. Güçlendirme Vakfı Yayın No:182, Bursa.

Aksoy, A., Macit, M., Karaoğlu, M., 2000. Hayvan Besleme, Atatürk Üniv. Ziraat Fak. Ofset Tesisi, Erzurum, 179-199.

Akyıldız, A. R., Atay, D., Erdem, A.,1974. Çayır, Mer'a ve Diğer Yem Bitkilerinde Değişik şartlarda Makro ve Mikro Elementler Üzerinde Araştırmalar, TÜBİTAK, TOAG-141, Ankara.

Alp, M., Kahraman, R., Kocabağlı, N., Özçelik, D., Eren, M., Türkmen, İ., Yavuz, M., Dursun, Ş., 2001. Marmara Bölgesi'ndeki Yem Bitkilerinin Mineral Madde Düzeylerinin Saptanması ve Koyunlarda Beslenme Bozuklukları İle İlişkisi. Turk J. Vet. Anim. Sci., 25, 511-520.

Altın, M., 1992. Çayır-Mera Islahı. Trakya Üniv. Tekirdağ Ziraat Fak. Yayın No: 152, Ders Kitabı No: 13 , Tekirdağ.

A.O.A.C., 1990. Official Method of Anallysis. Association of Official Analytical Chemists pp. 66-88. 15th.edition Washington, DC. USA.

Bakoğlu, A., Koç, A., Gökkuş, A., 1999. Erzurum Yöresi Çayır ve Meralarındaki Yaygın Bitki Türlerinin Ömür Uzunluğu, Çiçeklenmeye Başlama Tarihi ve Ot Kalitesi İle İlgili Bazı Özellikleri. Tr. J. Of Agriculture and Foresty, 23 (4), 951-957.

Başaran, U., Acar, Z., Mut, H., Aşc1, Ö.Ö., 2006. Doğal Olarak Yetişen Bazı Baklagil Yem bitkilerinin Bazı Morfolojik ve Tarımsal Özellikleri. OMÜ Zir. Fak. Derg. 21:3, 314-317.

Bayraktar, E., 2005. Tekirdağ Koşullarında Bazı Yem bitkilerinin Farklı Gelişme Dönemlerinde Kök ve Gövde lerinde Bitkilerin Kimi Besin Maddelerinin Değişimi. Yüksek Lisans Tezi. Tarla Bitkileri Ana Bilim Dalı, Tekirdağ.

Boğa, M., Filik, G., 2011. Ruminant Hayvan Beslemede Organik İz Minerallerin Önemi. (Derleme) Lalahan Hay. Araşt. Enst. Derg., 51 (1), 31-40.

Canbolat, Ö., Karaman, Ş., 2009. Bazı Baklagil Kaba Yemlerinin in Vitro Gaz Üretimi, Organik Madde Sindirilebilirliği, Nispi Yem Değeri ve Metabolik Enerji İçeriklerinin Karşılaştırılması. Tarım Bilimleri Dergisi, 15 (2), 188-195. Ankara.

Church D. C., 1991. Livestock Feeds and Feeding, Second Ed., A Reston Book Prentice-Hall, Englewood Cliffs New Jersey, 67-9.

Çimrin, T., Demirel, M., 2012. Kanatlı Karma Yemlerinde Bor Elementlerinin Kullanımı. Yüzüncü Yıl Üniv. Fen Bil. Enst. Derg., J.of Inst.of Natural \& Applied Sci.,17:1, 46-56.

Demir, B.S., 2005. Borun İnsan ve Bitki İçin Önemi ve Bazı Üzüm Çeşitlerinde Bor Tayini. Yüksek Lisans Tezi, Çukurova Üniv. Fen Bil. Enst., Adana.

Duncan, D.B., 1955. Mutiple Range and Multiple F Tests. Biometrics, 11, 1-42.

Kaçar, B., Katkat, A.V., 1997. Tarımda Fosfor. Bursa Ticaret Borsası Yayı nları No: 5, Bursa

Kızılgöz, İ., 2009. Kizılcadağ Yöresindeki Bazaltik Toprakların Arpa (Hordeum Vulgare L.) Bitkilerinin Bor Kapsamları Üzerine Etkileri. HR.Ü.Z.F. Dergisi, 13 (2), 15-20.

Kowalenko, C.G., 1978. Organic Nitrogen, Phosphorus and Sulfur in Soils. In: M. Schnitzer and S. U. Khon (Eds) Soil Organic Matter. Elsevier Publ. Comp., 95-136.

Kutlu, H.R., Görgülü, M., Çelik, B.M., 2005. Genel Hayvan Besleme. Çukurova Üniversitesi Ziraat Fakültesi Zootekni Bölümü. Ders notu. Adana.

Marschner, H., 1997. Mineral Nutrition of Higher Plants. (2. nd ed.) Academic press. 24-28 Oval Road London NW1 7DX.

Mayland, H.F., Cheeke, P.R., 1995. Forage-İnducedanimal disorders. In : R. F. Barnes, D. A. Miller and Nelson C. J. (Eds) Forages, Iowa State Univ. Press, Ames, Iowa, p. 147-162.

Mc Donald, P., Edwards, R. A., Greenhalgh, J. F. D., 1995. Animal Nutrition, Fifth Ed., Longman Scientific \& Technical Longman Group UK Ltd, Longman House, Burnt Mill, Harlow, Essex CM20 2JE, England, 97

Mertens, D., 2005a. AOAC Official Method 922.02. Plants Preparation of Laboratuary Sample. Official Methods of Analysis, 18th edn. Horwitz, W., and G.W. Latimer, (Eds). Chapter 3, pp1-2, AOAC-International Suite 500, 481. North Frederick Avenue, Gaitherburg, Maryland 20877-2417, USA.

Mertens, D., 2005b. AOAC Official Method 975.03. Metal in Plants and Pet Foods. Official Methods of Analysis, 18th edn. Horwitz, W., and G.W. Latimer, (Eds). Chapter 3, pp 3-4, AOAC-International Suite 500, 481. North Frederick Avenue, Gaitherburg, Maryland 20877-2417, USA. 
Murillo, M., Herrera, E., Carrete, F.O., Ruiz, O., 2012. Serrato, J.S., Chemical Composition, In vitro Gas Production, Ruminal Fermentation and Degradation Patterns of Diets by Grazing Steers in Native Range of North Mexico. Asian-Aust. J. Anim. Sci. 25 (10), 1395-1403.

Nielsen, F.H., 1994. Biochemical and Physiologic Consequences of Boron Deprivation in Humans, Environ Health Perapect, 102 Suppl 7, 59-63.

Orak. A., Ateş, E., Varol, F., 2004. Macar Fiği (Vicia pannonica Crantz.)'nin Farklı Gelişme Dönemlerindeki Bazı Morfolojik ve Tarımsal Özellikleri ile Besin İçeriği İlişkileri. Tarım Bilimleri Dergisi, 10(4), 410415.

Ozan. K., 1983. Genel Toksikoloji Ders Notları İstanbul.

Statistica, 1993. Statistica for Windows (Release 4.3), Sat Soft, Inc. Tulsa. OK.

Tekeli, A.S., Avcıŏlu, R., Ateş, E., 2003. İran Üçgülü (Trifolium resupinatum L.)'nde Bazı Morfolojik ve Kimyasal Özelliklerin Zamana ve Toprak Üstü Biomasına Bağlı Olarak Değișimi. Tarım Bilimleri Dergisi, 9(3), 352-360.

Türkmen, İ., Biricik, H., Deniz, G., Gezen, Ş.Ş., Tuncer, D., Çolpan, İ., Küçükersan, K., Küçükersan, S., Yalçın, S., Şehu, A., Saçaklı, P., Ergün, A., Yıldız, G., 2011. Temel Yem Bilgisi ve Hayvan Besleme, Anadolu Üniv., Web Ofset, Eskișehir, 16-18.

Underwood, E.J., 1981. The mineral Nutrition of Livestock. (Second Edition ) Commonwealth Agricultural Bureaux. Fernham Royal, England.

Warly, L., Evitayani, Fariani, A., 2010. Concentration of Micro Minerals in Fiber Fraction of Forages. World Academy of Science Engineering and Technology, 44, 1206-1212.

Zia-Ul-Haq, M., Shahıd, S.A., Ahmad, S., Qayum, M., Rasool, N., 2012. Mineral Contents and Antioxidant Potantial of Selected Legumes of Pakistan. J. of Medical Plants Research, Vol. 6 (32), 4735-4740. 